\title{
Gayrimenkul yatırım ortaklıklarının kârlılık oranlarının borsa performansına etkisi
}

\author{
The effect of profitability ratios of real estate investment trusts \\ on stock market performance
}

\author{
Salih Durer $^{1}$ (D) Ayşegül Berrak Köten ${ }^{2}$ \\ 1 Prof. Dr., Yıldız Teknik Üniversitesi, İktisadi ve İdari Bilimler Fakültesi, İşletme Bölümü, İstanbul, TÜRKİYE, e-mail: durer@yildiz.edu.tr \\ 2 PHDc, Yıldız Teknik Üniversitesi, Sosyal Bilimler Enstitüsü, İşletme Yönetimi, İstanbul, TÜRKIYYE, e-mail: a.berrak@gmail.com
}

$\ddot{O} z$

Gayrimenkul Yatırım Ortaklığı (GYO), halka açılma yoluyla toplanan fonların gayrimenkul sektörüne kanalize edilmesi suretiyle belli bir miktardaki birikimleri ile gayrimenkule yönelik yatırımda bulunmak isteyen tasarruf sahiplerinin meydana gelen değer artışından yararlanmaları bakımından önem taşımaktadır. Böylelikle GYOlar, yatırımcıların yalnız başlarına satın alımlarını gerçekleştiremeyecekleri gayrimenkullere ortak olabilme imkânı sunmaktadır. Özellikle, gelişmekte olan ülkelerde gayrimenkul yatırımları, diğer yatırım alanlarına göre daha az riskli olmaları ve yatırımcılara uzun vadede daha yüksek getiri sağlamaları nedeniyle yatırımcılar için daha cazip görünmektedir. Ayrıca, GYO'ların kârlılık oranlarının borsa performanslarını nasıl ve ne yönde etkileyeceğ $i$ de yatırımcılar için önemlidir. Türkiye'de son yıllarda gayrimenkul sektöründe gözlemlenen hareketlilik, yatırımcıların gayrimenkul projelerine yönelmelerinin yanı sıra GYO'lara yatırımda bulunarak kazanç sağlama arzuları, bu sektörde faaliyette bulunan şirketlerin başarımlarını yakınen takip etmeyi zorunlu kılar. Buradan yola çıarak, Borsa İstanbul'da işlem gören GYO'ların kârlılık oranlarının borsa performans göstergesi olan piyasa değeri/defter değgeriyle (PD/DD) ilişkisi panel regresyon analizi yardımıyla analiz edilmiştir. Analiz sonucunda, vergi öncesi kâr/öz kaynak oranı ve kümülatif kârlılık oran PD/DD değişkeni üzerinde anlamlı ilişkili değildir. Buna karşılık, faaliyet kârı/net satış oranı, faaliyet kârı/varlık oranı, net kâr/özkaynak oranı ve net kâr/varlık toplam oranı PD/DD değ işkeni üzerinde olumlu yönde anlaml ilişkilidir.

Anahtar kelimeler: GYO'lar, kârlılık oranları, borsa performansı, panel regresyon analizi

Jel kodlari: M21, G00, C21

\section{Abstract}

Real Estate Investment Trust (REIT) is important in terms of enabling individuals who want to invest in real estate with their limited savings to benefit from the resulting increase in value by directing the funds collected through public offering to the real estate sector. In this way, REITs allow investors to become partners in real estates that they cannot act alone. Especially in the developing countries, real estate investments seem to be more attractive to investors as they are less risky than other investment instruments and provide investors with higher returns in the long run. In addition, it is important for investors how and in what way the profitability ratios of REITs will affect their stock market performance. The dynamism observed in the real estate sector in Turkey in recent years, the investors' desire to earn income by investing in REITs as well as their tendency to real estate projects require close monitoring of the performances of companies operating in this sector. From this point of view, the relationship between the profitability ratios of REITS traded in Borsa Istanbul and the market value/book value (MV/BV), which is the stock market performance indicator, was analyzed with the help of panel regression analysis. As a result of the analysis, profit before tax/equity ratio and cumulative profitability ratio are not significantly related on the MV/BV variable. On the other hand, operating profit/net sales ratio, operating incomelasset ratio, net profitlequity ratio and net incomelasset total ratio are positively and significantly correlated on the MV/BV variable.

Keywords: reits, profitability ratios, stock market performance, panel regression analysis

Jel codes: M21, G00, C21

Citation/Atıf: DURER S. \& KÖTEN A. B. (2021).Gayrimenkul yatırım ortaklıklarının kârlılık oranlarının borsa performansına etkisi. Journal of Life Economics. 8(3): 379-388, DOI: $10.15637 /$ jlecon.8.3.09

Bu derginin içeriŏi Creative Commons Attribution-NonCommercial 4.0 Uluslararası Lisansı altında lisanslanmıştır. Content of this journal is licensed under a Creative Commons Attribution-NonCommercial 4.0 International License. 


\section{GİRIŞ}

Gayrimenkul Yatırım Ortaklıkları (GYO'lar), küçük yatırımcılara profesyonelce yönetilen gayrimenkullere erişim sağlamayı amaçlayan, 1960 yılında Amerika Birleşik Devletleri'nde çıkarılan Gayrimenkul Yatırım Ortaklığı Yasası'nın bir sonucu olarak 1961 yılında faaliyetlerine başladı (Burch \& Taylor, 1997). 1995 yılında Türkiye'de yasal düzenlemeler sonucu oluşturulan GYO'lar 1997 yılında borsaya kote olan şirketler arasında yer aldı. GYO'lar, gayrimenkuller, gayrimenkul projeleri, gayrimenkule dayalı haklar, sermaye piyasası araçları ve Sermaye Piyasası Kurulu tarafından belirlenecek diğer varlık ve haklardan oluşan portföyü işletmek amacıyla paylarını ihraç etmek üzere kurulan sermaye piyasası kurumlarıdır. Gayrimenkul yatırımları özellikle gelişmekte olan ülkelerde, diğer yatırım araçlarına göre daha az riskli olmaları ve yatırımcılara uzun vadede daha yüksek getiri sağlamaları nedeniyle yatırımcılar açısından daha cazip bir yatırım alanı olarak görülmüştür. Son yıllarda Türkiye'deki inşaat sektörünün gelişimi, gayrimenkul sektöründe yaşanan hareketlilik, büyük projelerin yapılması, yatırımcıların GYO'lara yatırımda bulunarak kazanım sağlama arzuları bu sektörde faaliyette bulunan kuruluşların başarımlarını yakınen takip etmeyi zorunlu kılmaktadır. GYO'ların finansal performanslarının incelenmesi yatırımcların kararlarını daha iyi analiz etmelerine katkı sağlayacaktır.

Bir GYO kuruluşu olmanın temel avantajı, esas olarak kurumlar vergisi muafiyetinden gelmektedir (Chan vd., 2003). GYO hisseleri borsalarda işlem gördüklerinden dolayı likiditeden ödün vermeden gayrimenkul yatırımı yapmanın bir yolunu arayan kurumsal yatırımcılar için de caziptir (Beals \& Singh, 2002). Ancak, vergi muafiyeti statüsünü sürdürmek için bir GYO'nun varlık bileşimi, gelir kaynağı, zorunlu gelir dağılımı ve mülkiyet çeşitlendirmesi ile ilgili mevzuat gereksinimlerini karşılaması gerekir (Zietz vd., 2003).

“Tasarruflarını gayrimenkul alanında değerlendirmek isteyen kurumsal yatırımcılar, GYO firmaları arasında seçim yaparken, nakit akışı sürdürülebilir, aktif yapısı sağlıklı, kârlılığı yüksek, kur ve faiz risklerine göre gerekli korunma mekanizmalarını kullanan, portföyünü çeşitlendirmiş, dengeli büyüme hızına sahip, kısacas1; finansal oranları kuvvetli ve borsa performansı yüksek firmaları tercih etme eğiliminde olmaktadır. Bu doğrultuda, yatırım yapılacak GYO'ların finansal verilerinin bütünüyle ele alınarak analiz edilmesi, mevcut durumlarının tespit edilmesi ve geleceğe yönelik varsayımların yapılması gerekmektedir" (Çelik \& Arslanlı, 2020: 256). 9 Ekim 2020 tarihli 31269 sayılı Resmî Gazete'de yayınlanan III-48.1.e sayılı Gayrimenkul Yatırım Ortaklıklarına İlişkin Esaslar Tebliği (III-48.1)'nde Değişiklik Yapılmasına Dair Tebliğ ile SPK mevzuatının genel olarak gelişmesiyle daha sade ve GYO sektörünün ihtiyaçlarına paralel olarak birçok maddede bir mevzuat düzenlemesi yapılmıştır. Yapılan bu revizyon ve değişikliklerle GYO'ların performanslarını artıcı yönde bir gelişme sağlanması da beklenebilir. Bu doğrultuda bu çalışmanın amacı, Borsa İstanbul A. Ş.'de (BİAŞ) işlem gören GYO'ların kârlılık oranlarının borsa performansına etkisinin panel regresyon yardımıyla belirlenmesidir.

\section{GAYRIMENKUL YATIRIM ORTAKLIKLARINDA KÂRLILIK ORANLARININ ÖNEMI VE İLGİLI LITTERATÜR}

Finans literatüründe GYO'ların finansal rasyolarının borsa performansına etkisini inceleyen birçok çalışma yapılmıştır, ancak spesifik olarak karlılık oranlarına odaklanan araştırmaların sayısı görece daha azdır.

Ocak 1990'dan Aralık 2001'e kadar Nasdaq ve NYSE'de işlem gören 187 GYO örneğini araştırdıkları çalışmalarında Ambrose vd. (2005), büyüme beklentilerini, gelir ve gider ölçümlerini, karlılık oranlarını, sistematik risk ve sermaye maliyetlerini inceleyerek GYO'larda ölçek ekonomilerini test ederler. Analiz sonucunda genel olarak, büyük GYO'ların, maliyetleri düşürmeyi başarırken büyüme beklentilerini artırd1ğını ve firma karlılığı ile firma büyüklüğü arasında doğrudan bir ilişkiye yol açtığını bulurlar. Ayrıca Ambrose vd. (2019), Avrupa gayrimenkul şirketlerinde de 2001 - 2015 dönemi için ölçek ekonomilerini araştırırlar. Avrupa genelinde 232 gayrimenkul şirketinden/GYO'dan oluşan bir örnek üzerinde panel veri regresyonunu kullanarak büyüklügüun gelir, gider, kârlılık oranları ve sermaye maliyetleri üzerindeki etkilerini analiz ederler. Çalışmalarında Avrupa'daki daha büyük emlak şirketlerinin, şirket büyüklüğü başına daha yüksek gelire ulaşabildiği, daha düşük maliyetlere katlanabildiği ve daha yüksek getiri elde edebildiği sonucuna ulaşırlar. Net faaliyet geliri oranları ve getiri oranları bir şirketin büyüklügü ile artarken satış, genel ve idari gider oranları azalır.

GYO'ların performanslarının çarpan etkisiyle diğer ilgili alt sektörlerin de gelişimini etkilemesi, sermaye piyasalarının derinleşmesine ve ekonomik büyümeye önemli katkı sağlamaktadır. Etkin karma yatırım portföylerine GYO'ların eklenmesinin sebeplerinden biri gayrimenkullerin enflasyona karşı korunma yetisidir (Fatnassi vd., 2014, 17). GYO'ların büyümesi, öteki piyasaların (inşaat, sağlık, turizm vb.) gelişimine de katkıda bulunmaktadır. Bu sayede, diğer piyasalarda oluşacak hareketlilik ve canlılık, istihdam ve gelir etkileri yaratarak iktisadi faaliyetlerin artması için önemli bir fayda sağlayabilmektedir (Marfatia vd., 2017). 
Tablo 1: BİST’de İşlem Gören GYO’ların Toplam Piyasa Değerleri ve Halka Açıklık Oranı

\begin{tabular}{|l|c|c|c|c|c|c|c|c|c|c|}
\hline \multicolumn{1}{|c|}{ Yıl } & $\mathbf{2 0 1 2}$ & $\mathbf{2 0 1 3}$ & $\mathbf{2 0 1 4}$ & $\mathbf{2 0 1 5}$ & $\mathbf{2 0 1 6}$ & $\mathbf{2 0 1 7}$ & $\mathbf{2 0 1 8}$ & $\mathbf{2 0 1 9}$ & $\mathbf{2 0 2 0}$ & $\mathbf{2 0 2 1 - Q 1}$ \\
\hline $\begin{array}{l}\text { Piyasa Değeri } \\
\text { MilyonTL }\end{array}$ & 15.800 & 18.119 & 21.731 & 21.465 & 25.447 & 26.924 & 18.384 & 27.777 & 54.163 & 57.745 \\
\hline $\begin{array}{l}\text { Piyasa Değeri } \\
\text { Milyon \$ }\end{array}$ & 8.888 & 8.505 & 9.339 & 7.356 & 7.231 & 7.138 & 3.481 & 4.676 & 7.379 & 6935 \\
\hline $\begin{array}{l}\text { Halka Açıklık } \\
\text { Oranı \% }\end{array}$ & $38 \%$ & $51 \%$ & $52 \%$ & $52 \%$ & $51 \%$ & $50 \%$ & $53 \%$ & $53 \%$ & $53 \%$ & $56 \%$ \\
\hline
\end{tabular}

Kaynak: GYODER, Gösterge, Türkiye Gayrimenkul Sektörü 2021, 1. Çeyrek Raporu, Sayı: 24

2006 - 2010 yılları arasında ABD hariç birçok ülkede GYO halka arzlarının milyon ABD doları cinsinden ortalama büyüklüğü ve sayısını inceleyen Erol vd. (2020), Türkiye GYO'larının, TREIT halka arzlarının ortalama boyutunun 8 GYO için 192,04 milyon ABD Doları olduğunu ve Kanada, İngiltere, Fransa, Belçika, Malezya, Tayvan, Tayland ve Güney Kore için ortalama halka arz boyutundan daha büyük olduğunu iddia eder. Bu nedenle, Türkiye'deki GYO halka arz piyasası canlı ve uluslararası rekabet gücüne sahip olmuştur (Coşkun vd., 2021: 2232). Tablo 1'de görüleceği üzere son dönemde Borsa İstanbul'da halka açıklık oranları artan GYO'ların aynı zamanda piyasa değerleri de yükselme eğilimindedir.

Erol \& Tirtiroglu (2011) tarafından yapılan araştırmada, İstanbul Borsası'nda 1998 - 2007 tarihleri arasında işlem gören GYO şirketlerinin sermaye yapıları incelenerek borç oranları üzerinde etkisi bulunan temettü dağıtım uygulamaları ile parametrelerin borçlanmaya yönelik etkilerine yer verilmiştir. Tobit tahmin yönteminden yararlanılarak elde edilen araştırma sonuçlarına göre, şirketlerin karlılık ve enflasyon oranlarıyla borçlanma oranları arasında anlamlı ve negatif yönde; firmanın büyüklügü ile borçlanma oranı arasındaysa anlamlı ve pozitif doğrultuda bir ilgi belirlenmiştir.

Harrison vd. (2011), çalışmalarında 1990-2008 yılları arasında gayrimenkul yatırım ortaklığı (GYO) sermaye yapısı kararlarının belirleyicilerini inceler. NYSE, AMEX veya NASDAQ'da işlem gören toplam 473 firma gözleminden oluşan geniş bir örneklem kullanarak, maddi varlıkların kaldıraçla pozitif ilişkili olduğunu, buna karşın kârlılık ve piyasa-defter oranlarının negatif ilişkili olduğunu bulurlar.

Kârlılık, firmanın kaldıraç kararı üzerinde birden çok etki de yapabilir. Jensen (1986), eğer kurumsal kontrol piyasası güçlüyse, iyi firmaların kaldıraç kullanarak nakit akışlarını ödemeyi (böylece vekalet maliyetlerini azaltmayı) taahhüt etmeleri gerektiğini savunur. Benzer şekilde, trade-off (takas) teorisi altında, karlılık arttıkça finansal sıkıntı ile karşılaşma olasılığı azalmaktadır. Hiyerarşik düzen teorisi ise, kârlı firmaların hisse senedi ihracı ile ilgili olumsuz sinyalden kaçınmak isteyeceklerini ve bu nedenle finansal kaldıraç kullanımlarını artırmaya daha meyilli olacaklarını öne sürer (Harrison vd., 2011: 138). Öte yandan ku- rumsal kontrol piyasası zayıf veya etkisiz ise, Rajan \& Zingales (1995), yöneticilerin borcun disipline edici etkisinden kaçınmayı ve böylece kârlılık arttıkça finansal kaldıraç kullanımlarını azaltmayı tercih edeceklerini savunurlar. Bu kavramla tutarlı olarak, Titman \& Wessels (1988), Fama \& French (2002) ve Barclay, Smith \& Morellec (2006) daha kârlı firmaların daha düşük borç oranlarına sahip olduğunu bulmuşlardır. Baker ve Wurgler (2002) ise, kârlılığın borç oranlarını öncelikle kazançların elde tutulması yoluyla etkilediğini iddia etmektedir.

Demireli vd. (2014) tarafından 1998-2010 tarihleri arasında gerçekleştirilen araştırmada, aralarında GYO sektörünün de bulunduğu 5 sektörün işletme sermayesi unsurlarının sektörel karlılığa etkilerini inceler. Uyguladıkları panel regresyon analizinde cari oran, kaldıraç oranı ve dönen varlık / toplam aktif değişkenlerinin, bağımlı değişkenlerden aktif karlılığı ve öz sermaye karlılı̆̆ını açıklama noktasında istatistiksel yönden anlamlı oldukları tespit edilmiştir. Piyasa değeri / defter değeri verisini açıklama hususunda yalnızca satışların değişkeni anlamlı çıkarken; TOBINQ verisini açıklama noktasında ise likidite oranı, cari oran ve satışlar değişkeni istatistiksel olarak anlamlı bulunmuştur.

Jakpar vd. (2018), Malezya'da faaliyet gösteren GYO şirketlerinin karlılıklarını etkileyen unsurların belirlenmesi amacıyla panel veri analizini kullanmış ve 2008-2015 tarihleri arasında 8 GYO şirketinin verilerini tetkik etmiştir. Gerçekleştirilen bu çalışmada aktif karlılık bağımlı değişken; net varlık değeri, hisse başına getiri ve fiyat / kazanç $(\mathrm{F} / \mathrm{K})$ oranıysa bağımsız değişken grubunda incelenmiştir. Elde edilen analiz sonuçlarına göre, yalnızca hisse senedi getirisiyle aktif karlılık arasında anlamlı ve pozitif yönde bir ilgi belirlenmiş ve net varlık değeri ve $\mathrm{F} / \mathrm{K}$ oranı ile aktif karlılık arasındaysa anlamlı bir ilişkiye rastlanmamıştır.

Khairulanuwar \& Chuweni (2021), Malezya Gayrimenkul Yatırım Ortaklıkları'nın (M-GYO/M-REIT) 2014 - 2018 yılları arasındaki performans analizini inceledikleri araştırmalarında, ROA ile ROE verimlilik oranları açısından, İslami GYO'ların yatırımcılar için geleneksel GYO'lardan daha elverişli ve yüksek oranda alıcılı olduğu sonucuna ulaşırlar. 
Hisse senedi piyasalarında işlem gören diğer işletmelerde olduğu gibi GYO'ların hisse senedi fiyatları şirket temelli olan şirket başarımı, kazançlar, kar payları, karlılık, yönetim kurulunda meydana gelen değişiklik ile yeni yönetim oluşturulması, yeni varlıkların meydana gelmesi gibi etkenlerle beraber; enflasyon, faiz oranları, para arzı, döviz kuru, altın fiyatları, petrol fiyatları, sanayi üretim göstergeleri, dış ticaret dengesi ve ekonomik büyüme gibi makroekonomik parametreler tarafından da etki altında kalabilmektedir (Nguyen vd., 2019: 124).

Geliştirmiş oldukları konut, iş ve/veya alışveriş merkezi, otel ve sosyal tesis gibi büyük projelerde birbirinden farklı gayrimenkul yatırımlarında bulunabilmek adına GYO'ların, büyük ölçekte uzun dönemli yabancı kaynak gereksinimleri bulunmaktadır. İhtiyaçları olan fonu, finansal kurumlardan elde ettiklerinde GYO'ların azami düzeylerde finansal maliyetlere katlanmaları nedeniyle etkin karlılıkları ve öz kaynak karlılıkları düşük görünebilir. Öte yandan bu durum, yeni projelerin olduğunu ve kaynakların bu projelere aktarıldığını da gösterir. Sermaye piyasası düzenlemesi çerçevesinde paylarını halka arz etmek suretiyle finansal kaynak elde eden GYO'lar bu metot ile, izafi bir şekilde daha düşük düzeyde finansal giderlere katlanıp türlü projeleri gerçekleştirebilmektedir (Bouchouicha \& Ftiti, 2012: 1822; Liu vd., 2012:475; Şarkaya, 2007; Teker, 1996).

GYO’lar birikimlerini gayrimenkul ve gayrimenkule bağlı olan haklara kanalize etmeyi arzulayan yatırımcılara, kendilerinin bireysel bir biçimde sahiplenemeyecekleri taşınmazları kolektif olarak sahiplenme olanağ1 tanımaktadır. Böylece, yatırımcılar hem şirketin aktifinde bulunan varlıklardaki değer artışından hem de belirli dönemlerde dağıtılması planlanan temettüden pay alarak tasarruflarını aktif olarak değerlendirebileceklerdir (Brueggman \& Fisher, 2011: 89; Rodenholm \& De Bernardi, 2013: 34).

Finansal çevreler, yatırımcı karar eğiliminin kârlılığı yüksek firmalara doğru yönelim göstermekte olduğunu, GYO hisse senedi fiyatlarındaki hareketliliğe yönelik olarak kârlılık verilerinin ciddi derecede etkili olduğunu düşünmektedir. Söz konusu durum, kârlılık göstergelerinin yatırımcıların yargılarını etkileyebileceğini ortaya koymakta ve aynı zamanda çok sayıda araştırmacıyı hisse senedi performansıyla kârlılık arasındaki bağın incelenmesi noktasında motive etmektedir (Hao Fang vd., 2016: 243; Pierdzioch vd.,
2018: 164). Kârlılık oranlarındaki değişimlere ilişkin bilgilerin ulaşılabilir olmasından dolayı, yatırımcılar elde ettikleri veriler ile hisse senedi kazanımları üzerinde tahminlerde bulunmaktadırlar. Kârlılık göstergelerinde meydana gelen değişim haberleri karşısında piyasa tepkisi sonucu borsa endeksi etkilenerek kârlılık unsurlarıla borsa göstergesi arasında bir ilgi ortaya çıkmaktadır (Kariyawasam, 2019: 1899).

Gayrimenkul piyasasının önemli özelliklerinden birisi de makroekonomideki değişikliklere karşı duyarlı olmasıdır (Hepşen vd., 2017: 194). Türkiye'de finansal derinliğin yeterli olmaması ülkeyi iç ve dış finansal dalgalanmalar karşısında güçsüz bir duruma sürüklemektedir. Ülke ekonomisinin lokomotifi görevi gören inşaat sektörüyle bu sektöre dayalı gayrimenkul yatırımları da şüphesiz ki karşılaşılan çeşitli dalgalanmaların etkisi altında kalmaktadır. Olumsuz etkiler doğal olarak kârlılığı düşürücü bir sonuç doğuracaktır. Öte yandan Türkiye'deki GYO'ların 2019 yılı itibarıla işlem hacmi artan bir yapı izlediği Tablo 2'de görülmektedir. İşlem miktarının ve işlem değerinin artması, GYO'ların talep görmesinde ve kârlılıklarının yükselmesinde rol oynayabilir. Bu nedenle Türkiye'de GYO'ların yatırımcılar tarafından tercih edilmesi bu döngü içinde gerçekleşebilir.

\section{KÂRLILIK ORANLARININ GYO'LARIN BORSA PERFORMANSINA ETKISININ EKONOMETRIKK ANALIZİ}

\subsection{Araştırmanın Amacı ve Önemi}

Gayrimenkul ve inşaat sektörü ekonomide ortaya ç1kan bunalımlardan en erken etkilenen ve en son kurtulan sektör olma özelliği taşıdığından birçok riski de barındırdığı söylenebilir. Öte yandan, bu sektörde yaşanacak olası bir canlılık, ülke ekonomilerine önemli ölçüde katkıda bulunmakta ve milli gelir üzerinde de olumlu etkiler bırakmaktadır.

Günümüzde ekonomik ve finansal bunalımlar sık sık görülmekte, gayrimenkul ve inşaat sektörünün karşı karşıya kaldığı likidite ile devam eden büyüme sorunlarına yönelik bir çözüm niteliğinde olan GYO'ların finansal performans veya borsa başarımlarının ya da bu hususlara etki eden etkenlerin incelenmesi zorunlu hale gelmiştir. Söz konusu GYO'ların, portföy faaliyetleriyle yatırımları destekleyebilmeleri veya bireysel ve kurumsal yatırımcıları portföy yatırımlarına çekebilmeleri açısından GYO'ların incelenmesi ve tanıtılma-

Tablo 2: Borsa İstanbul'da İşlem Gören GYO'ların İşlem Hacimleri (Milyon)

\begin{tabular}{|l|l|l|l|l|l|l|l|r|r|}
\hline \multicolumn{1}{|c|}{ Yll } & $\mathbf{2 0 1 3}$ & $\mathbf{2 0 1 4}$ & $\mathbf{2 0 1 5}$ & $\mathbf{2 0 1 6}$ & $\mathbf{2 0 1 7}$ & $\mathbf{2 0 1 8}$ & $\mathbf{2 0 1 9}$ & $\mathbf{2 0 2 0}$ & $\mathbf{2 0 2 1 - Q 1}$ \\
\hline İșlem Miktarı & 15.669 & 18.255 & 14.587 & 15.356 & 32.351 & 26.701 & 48.836 & 189.698 & 59.000 \\
\hline İșlem Değeri TL & 34.113 & 38.088 & 33.581 & 37.003 & 74.348 & 49.174 & 70.436 & 445.147 & 173.392 \\
\hline İșlem Değeri \$ & 17.496 & 17.427 & 12.519 & 12.334 & 20.464 & 11.230 & 12.376 & 62.354 & 23.658 \\
\hline
\end{tabular}

Kaynak: GYODER, Gösterge, Türkiye Gayrimenkul Sektörü 2021, 1. Çeyrek Raporu, Sayı: 24 
Tablo 3: Panel Regresyonda Ele Alınan Değişkenler

\begin{tabular}{|l|l|}
\hline Değişkenler & Tanımı \\
\hline Net Kâr/Özkaynak Oranı & Bağımsız değişken \\
\hline Vergi Öncesi Kâr/Öz Kaynak Oranı & Bağımsız değişken \\
\hline Net Kâr/Varlık Toplam Oranı & Bağımsız değişken \\
\hline Faaliyet Kârı/Net Satıs Oranı & Bağımsız değişken \\
\hline Kümülatif Kârlılık Oranı & Bağımsız değişken \\
\hline Faaliyet Kârı/Varlık Oranı & Bağımsız değişken \\
\hline PD/DD Oranı (\%) & Bağımlı değişken \\
\hline
\end{tabular}

sı önem taşımaktadır. Bu çalışmanın amacı, sermaye piyasalarında önem arz eden GYO'ların borsa performansları üzerinde kârlılık değişkenlerinin etkisini panel regresyon analiz yöntemi yardımıyla ortaya koymaktır.

\section{2. Örneklem Seçimi ve Verilerin Tanıtımı}

Borsa İstanbul A.Ş.'de işlem gören, 33 Gayrimenkul Yatırım Ortaklığı bu analizin evrenini oluşturmaktadir. Ancak bu GYO'lar incelendiğinde, az işlem gören şirketlerin değişkenliği arttırdı ğı ve ortalamayı temsil etmediği görülmüştür. Bu nedenle, 6 GYO d1şarıda bırakılarak toplam 27 GYO seçilerek örneklem oluşturulmuştur. Yapılan analizde, [2014.Q1-2020.Q2] dönemi için üçer aylık veri bazında panel regresyon analizi uygulanmıştır. Borsa performans göstergesi olarak piyasa değeri/defter değeri (PD/DD) değişkeni bağımlı değişken şeklinde ele alınmıştır. Kârlılık oranı seçiminde literatür doğrultusunda farklı birçok değişken ele alınmış fakat çoklu doğrusal bağlantı sorunu yaşanması nedeniyle (VIF>5) bazı değişkenler dişarıda bırakılmıştır. Analizlerde STATA 16.0 sürümü kullanılmıştır. Analizde kullanılan değişkenler Tablo 3'te gösterilmiştir.

\subsection{Yatay Kesit Bağımlılığı ve Homojenlik Testleri}

Panel veri analizlerinin incelenmesi yapılırken ilk başta değişkenlerin homojen olup olmadıklarına bakılmalıdır. Buna bağlı olarak, değişkenlerin homojen veya heterojen nitelik taşıması, tatbik edilecek eşbütünleşme ve birim kök testlerinin yapısını farklılaştırmaktadır (Hsiao, 2003: 56). Pesaran \& Yamagata (2008) ve Pesaran vd. (2008) tarafından geliştirilen Homojenlik testi birinci nesil birim kök testlerinde hangilerinin kullanılacağı konusunda yol göstermektedir. Diğer yandan, yatay kesit bağımlılığının bulunması halinde, ikinci nesil birim kök testleri uygulamak gerekmektedir (Wooldridge, 2010: 67). Bu çalışmada, 27 şirket $(\mathrm{N}=27)$ ve 26 çeyreklik dönem $(\mathrm{T}=26)$ olduğundan, zaman boyutunun yatay kesit boyutundan küçük olması durumunda $(\mathrm{T}<\mathrm{N})$, Pesaran (2004) CDLM testiyle belirlenmektedir.

Yapılan testten elde edilen sonuçların olasılık değerleri $\% 5^{\prime}$ ten az olması nedeniyle hipotezin sıfır olması (eğim katsayıları homojendir) reddedilmiş bunun yanında, katsayıların heterojen olduğu tespit edilmiştir. Ayrıca birimler arasında yatay kesit bağımlılığı ortaya çıkmıştır $(\mathrm{p}<0.05)$.

\subsection{Birinci Nesil Panel Birim Kök Test Sonuçları}

Birinci nesil birim kök testleri; homojen ve heterojen olacak şekilde iki grupta incelenmektedir. Katsayıların heterojen olması nedeniyle heterojen model hipotezine bağlı olarak Maddala ve Wu (1999), Im, Pesaran ve Shin (2003), Choi'de (2001) birinci nesil birim kök testlerinin uygulandığı görülmektedir.

Tablo 4: Yatay Kesit Bağımlılığı ve Homojenlik Test Sonuçları

\begin{tabular}{|l|l|l|l|l|}
\hline Değişkenler & $\begin{array}{l}\text { CDLM } \\
\text { Test İstatistiği }\end{array}$ & $\begin{array}{l}\text { LMadj } \\
\text { Test İstatistiği }\end{array}$ & $\begin{array}{l}\text { CDLM } \\
\text { p değeri }\end{array}$ & $\begin{array}{l}\text { LMadj } \\
\text { p değeri }\end{array}$ \\
\hline Net Kar/Özkaynak Oranı & 5.372 & 7.458 & 0.001 & 0.005 \\
\hline Vergi Öncesi Kar/Öz Kaynak Oranı & 8.449 & 11.390 & 0.000 & 0.000 \\
\hline Net Kar/Varlık Toplam Oranı & 7.189 & 9.803 & 0.005 & 0.006 \\
\hline Faaliyet Kârı/Net Satış Oranı & 6.372 & 8.475 & 0.009 & 0.000 \\
\hline Kümülatif Kârlılık Oranı & 5.886 & 7.327 & 0.000 & 0.001 \\
\hline Faaliyet Kârı/Varlık Oranı & 8.221 & 10.567 & 0.003 & 0.000 \\
\hline PD/DD Oranı & 9.563 & 11.105 & 0.000 & 0.000 \\
\hline $\begin{array}{l}\text { Katsayı Homogenliği Testi } \\
\text { (İstatistik Değeri) }\end{array}$ & $\mathbf{\Delta}=18.453$ & $\mathbf{p}=0.000$ & \\
\cline { 2 - 5 } & $\mathbf{\Delta}_{\text {adj }}=21.566$ & $\mathbf{p}=0.006$ & \\
\hline
\end{tabular}


Tablo 5: Birinci Nesil Panel Birim Kök Testi Sonuçları

\begin{tabular}{|l|c|c|c|c|c|c|}
\hline \multirow{2}{*}{\multicolumn{1}{|c|}{ Değişkenler }} & \multicolumn{2}{|c|}{ Maddala\&Wu Test } & Im, Pesaran \& Shin Test & \multicolumn{2}{c|}{ Choi Test } \\
\cline { 2 - 7 } & Düzey & $\begin{array}{c}\text { 1. Mertebe } \\
\text { Fark }\end{array}$ & Düzey & $\begin{array}{c}\text { 1. Mertebe } \\
\text { Fark }\end{array}$ & Düzey & $\begin{array}{c}\text { 1. Mertebe } \\
\text { Fark }\end{array}$ \\
\cline { 2 - 7 } & Trend+Sabit & Sabit & Trend+Sabit & Sabit & Trend+Sabit & Sabit \\
\hline $\begin{array}{l}\text { Net Kâr/Özkaynak } \\
\text { Oranı }\end{array}$ & -0.852 & $-5.366^{*}$ & -0.953 & $-5.917^{*}$ & -1.131 & $-6.451^{*}$ \\
\hline $\begin{array}{l}\text { Vergi Öncesi Kâr/Öz } \\
\text { Kaynak Oranı }\end{array}$ & -1.109 & $-4.988^{*}$ & -1.231 & $-5.240^{*}$ & -1.255 & $-6.998^{*}$ \\
\hline $\begin{array}{l}\text { Net Kâr/Varık } \\
\text { Toplam Oranı }\end{array}$ & -0.995 & $-5.743^{*}$ & -1.102 & $-6.423^{*}$ & -1.219 & $-7.203^{*}$ \\
\hline $\begin{array}{l}\text { Faaliyet Kârı/Net } \\
\text { Satıș Oranı }\end{array}$ & -0.876 & $-7.226^{*}$ & -0.911 & $-7.895^{*}$ & -1.242 & $-8.124^{*}$ \\
\hline $\begin{array}{l}\text { Kümülatif Kârlılık } \\
\text { Oranı }\end{array}$ & -1.114 & $-6.809^{*}$ & -1.238 & $-7.301^{*}$ & -1.320 & $-8.262^{*}$ \\
\hline $\begin{array}{l}\text { Faaliyet Kârı/Varlık } \\
\text { Oranı }\end{array}$ & -0.945 & $-7.204^{*}$ & -1.105 & $-7.657^{*}$ & -1.114 & $-8.406^{*}$ \\
\hline PD/DD oranı & -1.134 & $-7.445^{*}$ & -1.217 & $-8.113^{*}$ & -1.278 & $-9.114^{*}$ \\
\hline
\end{tabular}

*0.05 için durağan değișken

Panel birim kök testleri sonucunda, birinci mertebe fark için değişkenlerin I (1) yani durağan olduğu belirlenmiştir. Bu durumda, analizde birinci mertebe farkları alınarak çalışılmıştır.

\section{5. İkinci Nesil Panel Birim Kök Test Sonuçları}

Panel verilerinde yatay kesit bağımlılı̆̆ının bulunması durumunda, ikinci nesil birim kök testlerinin uygulanması daha etkin, tutarlı ve sağlam tahminlerde bulunulmasına destek olmaktadır. Bu araştırmadan, yatay kesit bağımlılı̆̆ının belirlenmesi nedeniyle ikinci nesil birim kök testleri uygulanmalıdır (Özel vd., 2013: 168). İkinci nesil birim kök testlerinden biri olan CADF testinden yararlanılmıştır. Pesaran'ın (2007) geliştirmiş olduğu CADF testinden elde edilen verilen Tablo 6'da gösterilmiştir.

CADF testlerinde, azami gecikme uzunluğu 2 şeklinde alınarak en uygun gecikme uzunluğu Schwarz bilgi kriteri göz önünde bulundurularak tespit edilmiştir. Sıfır hipotezinin \%5 anlamlılık seviyesinde kabul edilmediği görülmektedir. Birim kök testinden elde edilen veriler, serilerin düzeyde sabit olmadıklarını başka bir deyişle içlerinde birim kök bulundurduklarını, değişkenlerin I (1) seviyesinde sabitlendiklerini açılamaktadır. Bu durumda birinci derece farkları kullanılarak regresyon analizi uygulanmıştır.

\subsection{Panel Regresyon Tahmin Sonuçları}

Panel veri tahmin yöntemleri; havuzlanmış, sabit ve tesadüfî etkilerle gerçekleştirilmektedir. Hangi yöntemin seçileceğinin belirlenmesi için ön testlere ihtiyaç vardır (Baltagi, 2005: 78). Panel regresyon tahmin süreci için ise, ilk aşamada Chow ve Breush-Pagan (BP) testleri uygulanmaktadır. Chow testi için, $\mathrm{H} 0$ hipotezi havuzlanmış regresyon (pooled) ve $\mathrm{H} 1$ hipotezi sabit etkiler modeliyken (SEM), BP testi için H0 hipotezi havuzlanmış regresyon ve $\mathrm{H} 1$ tesadüfi etkiler modelidir (TEM) (Bayar \& Sezgin, 2017: 55).

Tablo 7: Panel Regresyon Tahmin Yöntemi Seçim Test

\begin{tabular}{|l|l|l|}
\hline Test & Olasıllk $(\mathbf{p})$ & Karar \\
\hline Chow $(\mathrm{F}$ testi $)$ & 0.000 & $\mathrm{H}_{0}$ red \\
\hline $\mathrm{BP}\left(\mathrm{X}^{2}\right.$ testi $)$ & 0.002 & $\mathrm{H}_{0}$ red \\
\hline
\end{tabular}

\section{Sonuçları}

Yukarıdaki tabloda da görüldüğü gibi, her iki test için, H0 hipotezi reddedilmiştir. Dolayısıyla, TEM ve SEM modelleri arasında bir tercihte bulunma gereği du-

Tablo 6: Panel CADF Birim Kök Testi Sonuçları

\begin{tabular}{|l|l|l|l|l|}
\hline \multirow{2}{*}{\multicolumn{1}{c|}{ Değișkenler }} & \multicolumn{2}{c|}{ Düzey } & \multicolumn{2}{c|}{ 1. Mertebe Fark } \\
\cline { 2 - 5 } & \multicolumn{1}{c|}{ Sabit } & Sabit + Trend & \multicolumn{1}{c|}{ Sabit } & Sabit + Trend \\
\hline Net Kâr/Özkaynak Oranı & -0.934 & -1.037 & $-6.744^{*}$ & $-6.916^{*}$ \\
\hline Vergi Öncesi Kâr/Öz Kaynak Oranı & -0.863 & -0.966 & $-6.505^{*}$ & $-7.103^{*}$ \\
\hline Net Kâr/Varlık Toplam Oranı & -0.977 & -1.103 & $-7.365^{*}$ & $-8.235^{*}$ \\
\hline Faaliyet Kârı/Net Satıș Oranı & -0.842 & -0.987 & $-5.908^{*}$ & $-6.105^{*}$ \\
\hline Kümülatif Kârlılık Oranı & -1.214 & -1.299 & $-6.325^{*}$ & $-6.877^{*}$ \\
\hline Faaliyet Kârı/Varlık Oranı & -0.908 & -1.022 & $-6.202^{*}$ & $-6.514^{*}$ \\
\hline PD/DD oranı & -1.231 & -1.355 & $-7.454^{*}$ & $-7.916^{*}$ \\
\hline
\end{tabular}

*0.05 için durağan değișken 
Tablo 8: Hausman Testi Sonuçları

\begin{tabular}{|l|l|l|l|}
\hline Test Özeti & Ki-kare İstatistiği & Ki-kare s.d. & Olasıllk (p) \\
\hline Cross-section random & 642.134 & 2 & 0.000 \\
\hline Period random & 716.941 & 2 & 0.000 \\
\hline Cross-section and period random & 811.384 & 2 & 0.000 \\
\hline
\end{tabular}

yulmuştur. Bu durumda, Hausman testi yardımıyla iki model için seçim yapılacaktır. Bu testin hipotezleri aşağıda verilmiştir ve test sonuçları da Tablo 8'de sunulmuştur.

$$
\begin{aligned}
& \text { “ } \mathrm{H}_{0} \text { : Tesadüfi etki var (TEM)" } \\
& \text { “ } \mathrm{H}_{1} \text { : Tesadüfi etki yok (SEM)" }
\end{aligned}
$$

Yapılan Hausman test sonuçlarına göre, H1 hipotezi kabul edilerek, SEM modeline karar verilmiştir. Ayrıca bu model analiz edilirken, farklı çözüm algoritmaları uygulanmış ve toplam hata karesi minimum değerde olan "Cross section SUR algoritması" yla çalışılmıştır.

Regresyon sonuçlarında görüleceği üzere, bağımsız değişkenler, PD/DD değişkenini \%71.2 açıklama gücüne sahiptir. Kârlılık oranlarından vergi öncesi kâr/ öz kaynak oranı ve kümülatif kârlılık oranı istatistik anlamlı değildir ( $p>0.05)$. Bu iki kârlılık oranı dışında kalan değişkenler istatistik anlamlı sonuç vermiştir $(\mathrm{p}<0.05)$. Anlamlı çıan panel regresyon tahmin sonuçları katsayı büyüklüklerine göre kısaca şöyle sıralanmıştır:

Anlamlı değişkenlerde en büyük etki faaliyet karı/net satış oranı olmuştur.

Faaliyet karı/net satış oranı 1 birim arttığında, PD/DD değişkeni 0.453 birim artış göstermektedir.

Faaliyet kârı/varlık oranı 1 birim arttı̆̆ında, PD/DD değişkeni 0.329 birim artış göstermektedir.

Net kâr/özkaynak oranı 1 birim artığında, PD/DD oranı 0.184 birim artış göstermektedir.

Net kâr/varlık toplam oranı 1 birim artığında, PD/DD oranı 0.009 birim artış göstermektedir.

Modelde yer alan varsayımların test edilmesi amaciyla Wooldridge (2002) otokorelasyon testi uygulanarak otokorelasyonun olmadığı tespit edilmiştir. Greene heteroskedasite testinin sonucuna göre, homoskedasitenin var olduğu belirlenmiş ve varsayımların elde edildiği modelin sonuçlarının yorumlanır nitelik taş1dığı görülmüştür.

\begin{tabular}{|c|c|c|c|c|}
\hline \multicolumn{5}{|l|}{ Bağımlı Değișken: F(PD/DD) } \\
\hline \multicolumn{5}{|c|}{ Yöntem: Panel EGLS (çift yönlü sabit etkiler) } \\
\hline \multicolumn{5}{|c|}{ Örneklem: 2014.Q2 - 2020.Q2 } \\
\hline \multicolumn{5}{|l|}{ Yatay Kesit Sayısı: 27} \\
\hline \multicolumn{5}{|c|}{ Toplam Panel Gözlem (Dengeli) Sayısı: 593} \\
\hline Oranlar & Katsayı & Std. Hata & t-istatiği & Olasılık \\
\hline FNet Kar/Özkaynak Oranı & 0.184842 & 0.036689 & 5.038039 & $0.0000 *$ \\
\hline FVergi Öncesi Kar/Öz Kaynak Oranı & 2.886678 & 1.774223 & 1.627010 & 0.1054 \\
\hline FNet Kar/Varlık Toplam Oranı & 0.009270 & 0.003620 & 2.560804 & $0.0112 *$ \\
\hline FFaaliyet Kârı/Net Satıș Oranı & 0.453264 & 0.174963 & 2.590626 & $0.0103 *$ \\
\hline FKümülatif Kârlılık Oranı & 0.033014 & 0.038899 & 0.848731 & 0.3971 \\
\hline FFaaliyet Kârı/Varlık Oranı & 0.329192 & 0.038508 & 8.548747 & $0.0000 *$ \\
\hline Sabit & 8.945160 & 0.621535 & 14.39205 & $0.0000 *$ \\
\hline \multicolumn{5}{|c|}{$\begin{array}{lccc}R^{2}=0.712 & F_{\text {ist }}=34.68 & F(p)=0.000 & D W=2.10 \\
\text { Wooldridge }(p)=0.122 & \text { Greene Heteroskedasticity Test }(p)=0.367\end{array}$} \\
\hline
\end{tabular}

Tablo 9: Panel Regresyon Tahmin Sonuçları

*0.05 düzeyinde anlamlı değișken, "F" gösterimi 1 . mertebe farkı belirtmektedir. 


\section{SONUÇ}

$\mathrm{Bu}$ çalışmanın amacı, ülkemizde ciddi bir yere sahip gayrimenkul ve inşaat sektörünün temeli haline gelen GYO’lar için kârlılık oranlarının borsa performansları üzerindeki etkisini ortaya koymaktır. Analiz sonucunda, vergi öncesi kâr/öz kaynak oranı ve kümülatif kârlılık oranı PD/DD değişkeni üzerinde anlamlı ilişkili bulunmamıştır. Buna karşılık, faaliyet karı/net satış oranı, faaliyet karı/varlık oranı, net kar/özkaynak oranı ve net kar/varlık toplam oranı PD/DD değişkeni üzerinde olumlu yönde anlamlı ilişkili bulunmuştur.

Genel olarak değerlendirildiğinde, kârlılık artışının, mali yapının güçlenmesinin ve likidite artışının piyasa değeri/defter değerini olumlu etkilediği anlaşılmaktadır. GYO'lar halka arz edilerek, yeni yatırımlar, yeni projeler, türlü duran varlıklar ve portföylerinde var olabilecek her çeşit sermaye piyasası araçlarının tedarik edilmesine yönelik gereksinimleri olan finansal kaynağa erişebilmektedirler. Böylelikle, finansman maliyeti ve risk azaltılarak yeni yatırımlara fon aktarılmakta ve karlılık seviyelerinin daha da yükseltilmesi fırsatı yakalanmaktadır. GYO kuruluşlarının hukuki bir zorunluluk ve yükümlülüklerinin bulunmamasıyla beraber belirli zamanlarda sağladıkları kazanımlarını hissedarlarına temettü şeklinde dağıtımlarını yapmaktadırlar. Bu durumda yatırımcılar için, faaliyet kârı ve bunun satışlara oranı, diğer yandan net kâr ve bunun varlıklara oranı gibi göstergeler yatırımlardan beklenen verimin alındığını ortaya koymaktadır. $\mathrm{Bu}$ durum GYO hisselerine olan talebi artırıcı rol oynamaktadır. Kârlılık arttığında, yeni yatırımlardan beklenen kârlılığın elde edildiği anlaşılır ve likidite problemi yaşanmadığ 1 düşününülür. Bu görüş yatırımcılar için çekici güç olmakta ve hisseye talebi arttırmaktadır. GYO'ların karlılığı artırıcı yatırımlar gerçekleştirmesi aynı zamanda bir itibar yaratmaktadır.

Her geçen dönem performanslarında yükseliş ivmesi gözlense de GYO'ların BİAŞ'de genel olarak yeteri kadar talep yaratamadığı görülmekte, derinlik ve genişlik açısından görece sığ bir piyasa olduğu algısının tam olarak değişemediği izlenmektedir. Gayrimenkul sektörü, ekonomi ve piyasa dinamiklerine karşı oldukça kırılgan bir yapıda olup, olumlu ya da olumsuz gelişmelerden çok hızlı bir şekilde etkilenmektedir. Az gelişmiş veya gelişmekte olan ekonomilerde sermaye yatırımları gerektiği gibi ilerleme gösteremediğinden finansal kaynak temininde ve alternatif sermaye piyasası araçları geliştirmede henüz yeterince yol katedilemediği anlaşılmaktadır. Halbuki, bir ekonomide itici gücü finans sektörü meydana getirmekte ve tasarruf sahiplerinin arttırımlarının ekonomiye kazandırılmas1 yönünde çaba gösterilmektedir. Dünya genelinde gayrimenkulle ilişkili sektörlerin ekonomideki payı oldukça büyüktür. Bu değerli yatırım araçlarından yararlanabilmek adına, ülkemizde gayrimenkul ile bağlantılı finansal araçların çeşitlendirilmesi yoluna gidilmelidir. Politika yapıcıların hisse senedi piyasasının ilerlemesi ve ekonomik büyümeye üzerindeki desteğini çoğaltmak amaçli politikalar meydana getirmesi ve bu yönde makro değişkenler üzerindeki istenmeyen gelişmeleri yapısal reformlar üzerinden doğru biçimde yönetmesi beklenir. Bunun yanı sıra, uzun vadede hisse senedi kazanımları üzerinde etkili olan unsurların sabit kalmayabileceği, zaman içinde ve finansal konjontüre göre değişebileceği ön planda tutularak ileriki zamanlarda gerçekleştirilecek araştırmalarda başka kârlılık oranlarıyla beraber başka borsa performans göstergeleri üzerindeki etkisinin farklı ekonometrik yöntemlerle incelenmesi uygun olabilecektir.

\section{KAYNAKÇA}

AMBROSE, B. W., HIGHFIELD, M. J. \& LINNEMAN, P. D. (2005). Real estate and economies of scale: The case of REITs. Real Estate Economics, 33 (2), 323-350. https://doi. org/10.1111/j.1540-6229.2005.00121.x

AMBROSE, B. W., FUERST, F., MANSLEY, N. \& WANG, Z. (2019). Size effects and economies of scale in European real estate companies. Global Finance Journal, 42, (Article Number: 100470), 1-17. https://doi.org/10.1016/j. gfj.2019.04.004

BAKER, M. \& WURGLER, J. (2002). Market timing and capital structure. The Journal of Finance, 57(1), 1-32. https://doi.org/10.1111/1540-6261.00414

BALTAGI, B. H. (2005). Econometric Analysis of Panel Data. 3rd Edition. West Sussex: John Wiley \& Sons Ltd.

BARCLAY, M. J., SMITH, C.W. JR., \& MORELLEC, E. (2006). On the debt capacity of growth options. The Journal of Business, 79(1), 37-59. https://doi.org/10.1086/497404

BAYAR Y. \& SEZGIN H. F. (2017). Trade openness, inequality and poverty in Latin American countries. Ekonomika (Economics), 96(1), 47-57. https://doi.org/10.15388/ ekon.2017.1.10663

BEALS, P. \& SINGH, A. J. (2002). The evolution and development of equity REITS: The securitization of equity structures for financing the U.S. lodging industry. The Journal of Hospitality Financial Management, 10 (1), 15-33. Article 3. Available at: https://scholarworks.umass.edu/jhfm/ vol10/iss $1 / 3$

BOUCHOUICHA, R. \& FTITI, Z., (2012). Real estate markets and the macroeconomy: A dynamic coherence framework, Economic Modelling, Elsevier, 29(5), 1820-1829. https://doi.org/10.1016/j.econmod.2012.05.034

BRUEGGMAN, W. B. \& FISHER, J. D. (2011). Real estate 
finance and investments, $4^{\text {nd }}$ Edition, New York: McGrawhill Pbc.

BURCH, R. K. \& TAYLOR, R. S., (1997). The internal conflicts of hotel REITs. Real Estate Review, 27 (3), 10-18.

CHAN, S. H., ERICKSON, J. \& WANG, K., (2003). Real estate investment trusts: Structure, performance, and investment opportunities. New York: Oxford University Press.

CHOI, I. (2001). Unit root tests for panel data. Journal of International Money and Finance, 20(2), 249-272. https:// doi.org/10.1016/S0261-5606(00)00048-6

COSKUN, Y., EROL, I. \& MORRI, G. (2021). Why do Turkish REITs trade at discount to net asset value? Empirical Economics, 60, 2227-2259. https://doi.org/10.1007/ s00181-020-01846-y

ÇELIK, E. \& ARSLANLI, K. Y. (2020). Gayrimenkul yatırım ortaklığı firmalarının piyasa değeri ve aktif karlılığını etkileyen finansal oranların panel veri analizi yöntemiyle belirlenmesi. Muhasebe ve Finansman Dergisi - Ekim/2020, (88): 255-274. https://doi.org/10.25095/ mufad.801491

DEMIRELI, E., BASCI, E. S. \& KARACA, S. S. (2014). İșletme sermayesi ve performans göstergeleri arasındaki ilişkiler: Borsa İstanbul üzerine bir uygulama. Ege Stratejik Araştırmalar Dergisi, 5(1), 79-98. https://doi.org/10.18354/ esam. 19583

EROL, I. \& TIRTIROGLU, D. (2011). Concentrated ownership, no dividend payout requirement and capital structure of REITs: Evidence from Turkey. The Journal of Real Estate Finance and Economics, 43(1-2), 174-204. https:// doi.org/10.1007/s11146-010-9242-7

EROL, I., TIRTIROGLU, D., \& TIRTIROGLU, E. (2020). Pricing of IPOs under legally-mandated concentrated ownership and commitment period: Evidence from a natural experiment for REITs in Turkey. Journal of Behavioral and Experimental Finance, 25 (Article number: 100245), 1-15. https://doi.org/10.1016/j.jbef.2019.100245

FAMA, E. F. \& FRENCH, K. R. (2002). Testing trade-off and pecking order predictions about dividends and debt. The Review of Financial Studies, 15(1), 1-33. Retrieved May 15, 2021, from http://www.jstor.org/stable/2696797

FANG, H., CHANG, T-Y., LEE, Y-H \& CHEN, W-J. (2016). The impact of macroeconomic factors on the real estate investment trust index return on Japan, 36 Singapore and China. Investment Management and Financial Innovations, 13(4-1), 242-253. https://doi.org/10.21511/imfi.13(41). 2016.11

FATNASSI, I., SLIM, C., FTITI, Z., \& MAATOUG, A. B. (2014). Effects of monetary policy on the REIT returns: Evidence from the United Kingdom. Research in International Business and Finance, 32, 15-26. https://doi.org/10.1016/j. ribaf.2014.01.001

Gayrimenkul Yatırım Ortaklıklarına İlişkin Esaslar Tebli- ği (III-48.1), 28 May1s 2013 Sal1, Say1: 28660. Retrieved May 15, 2021, from https://www.resmigazete.gov.tr/eskiler/2013/05/20130528-14.htm

Gayrimenkul Yatırım Ortaklıklarına İlişkin Esaslar Tebliği (III-48.1)'nde Değişiklik Yapılmasına Dair Tebliğ (III-48.1.e) 9 Ekim 2020 Cuma, Say1: 31269. Retrieved May 15, 2021, from. https://www.resmigazete.gov.tr/eskiler/2020/10/20201009-15.htm

GYODER, GOSTERGE, (2021). Gyoder, Gösterge, Türkiye Gayrimenkul Sektörü 2021, 1. Çeyrek Raporu, Say1: 24, Gayrimenkul ve Gayrimenkul Yatırım Ortaklığı Derneği, İstanbul. (1-79) Retrieved May 15, 2021, from https://www. gyoder.org.tr/files/202106/636188ee-fdf1-40fc-81a0-46a688ae2b37.pdf

HARRISON, D. M., PANASIAN, C.A. \& SEILER, M. J. (2011). Further evidence on the capital structure of REITs. Real Estate Economics, 39(1), 133-166. https://doi.or$\mathrm{g} / 10.1111 / \mathrm{j} .1540-6229.2010 .00289 . \mathrm{x}$

HEPSEN, A., BERBEROGLU, M. G., \& AYDIN, O. (2017). Real estate investment trusts in Turkey: Structure, analysis, and strategy. Journal of Business Economics and Finance, 6(2), 191-199. https://doi.org/10.17261/Pressacademia.2017.508

HSIAO, C. (2003). Analysis of Panel Data (2nd ed., Econometric Society Monographs). Cambridge: Cambridge University Press.

IM, K. S., PESARAN, M. H., \& SHIN, Y. (2003). Testing for unit roots in heterogeneous panels. Journal of Econometrics, 115(1), 53-74. https://doi.org/10.1016/S03044076(03)00092-7

JAKPAR, S., TINGGI, M., TAK, A. H., \& RUZLAN, N. A. (2018). Determinant factors of profitability in Malaysia's real estate investment trusts (M-REITS). UNIMAS Review of Accounting and Finance, 2(1), 72-84. https://doi. org/10.33736/uraf.1209.2018

JENSEN, M. (1986). Agency costs of free cash flow, corporate finance, and takeovers. The American Economic Review, 76(2), 323-329. Retrieved May 15, 2021, from. http://www.jstor.org/ stable/1818789

KARIYAWASAM, H. N. (2019). Analysing the impact of financial ratios on a company's financial performance. International Journal of Management Excellence, 13(1), 1898-1903. https://doi.org/10.17722/ijme.v13i1.1093

KHAIRULANUWAR, A. J. \& CHUWENI, N. N. (2021). The significance and performance analysis of Malaysian real estate investment trusts. International Journal of Law and Management, 63(4), 417-430. https://doi.org/10.1108/ IJLMA-01-2020-0022

LIU, J., LOUDON, G., \& MILUNOVICH, G. (2012). Linkages between international REITs: The role of economic factors. Journal of Property Investment \& Finance, 30(5), 473-492. https://doi.org/10.1108/14635781211256747 
MADDALA, G. S. \& WU, S. (1999). A comparative study of unit root tests with panel data and a new simple test. Oxford Bulletin of Economics and Statistics, Special Issue, 61(S1), 631-652. https://doi.org/10.1111/1468-0084.0610s1631

MARFATIA, H. A., GUPTA, R., \& CAKAN, E. (2017). The international REIT's time-varying response to the U.S. monetary policy and macroeconomic surprises. The North American Journal of Economics and Finance, 42, 640-653. https://doi.org/10.1016/j.najef.2017.09.007

NGUYEN, M.-L. T., BUI, T. N., \& NGUYEN, T. Q. (2019). Relationships between real estate markets and economic growth in Vietnam. The Journal of Asian Finance, Economics and Business, 6(1), 121-128. https://doi.org/10.13106/ JAFEB.2019.VOL6.NO1.121

OZEL, H. A., SEZGIN, F. H. \& TOPKAYA, O. (2013). Investigation, of economic growth and unemployment relationship for G7 countries using panel regression analysis. International Journal of Business and Social Science, 4(6), 162-170. Retrieved from http://ijbssnet.com/journals/ Vol_4_No_6_June_2013/20.pdf

PESARAN, M. H. (2004). General diagnostic tests for cross section dependence in panels. CESifo Working Papers, (No. 1229) 1-40. https://doi.org/10.17863/CAM.5113 Retrieved from. https://www.cesifo.org/en/publikationen/2004/working-paper/general-diagnostic-tests-cross-section-dependence-panels

PESARAN, M. H. (2007). A simple panel unit root test in the presence of cross-section dependence. Journal of Applied Econometrics, 22(2), 265-312. https://doi.org/10.1002/ jae.951

PESARAN, M. H. \& YAMAGATA, T. (2008). Testing slope homogeneity in large panels. Journal of Econometrics, 142 (1), 50-93. https://doi.org/10.1016/j.jeconom.2007.05.010

PESARAN, M. H., ULLAH A., \& YAMAGATA T. (2008). A bias-adjusted LM test of error cross-section independence. Econometrics Journal, 11 (1), 105-127. https://doi.org/10.1111/j.1368-423X.2007.00227.x

PIERDZIOCH, C., RISSE, M., GUPTA, R., \& NYAKABAWO, W. (2018). On REIT returns and (un-) expected inflation: Empirical evidence based on Bayesian additive regression trees. Finance Research Letters, Elsevier, 30 (C), 160-169. https://doi.org/10.1016/j.frl.2018.09.010

RAJAN, R. G. \& ZINGALES, L. (1995). What do we know about capital structure? Some evidence from international data. The Journal of Finance, 50(5), 1421-1460. https://doi. org/10.1111/j.1540-6261.1995.tb05184.x

RODENHOLM, R., \& DE BERNARDI, D. (2013). Macroeconomic effects on securitized real estate markets: A comparative study of Sweden and Switzerland (Dissertation). Retrieved from http://urn.kb.se/resolve?urn=urn:nbn:se:kth:diva-124109

SARKAYA, C. (2007). Gayrimenkul yatırım ortaklıkları üzerine bir inceleme ve Türkiye'ye ilişkin sektör analizi.
Sosyal Bilimler Dergisi (1), 175-190. Retrieved from https://dergipark.org.tr/tr/pub/iusosbil/issue/9503/118781

TEKER, M. B. (1996). Sermaye piyasası araçları yoluyla gayrimenkul finansmanı ve yatırımı. Yayın No: 43, Ankara: Sermaye Piyasası Kurulu Yayınları.

TITMAN, S. \& WESSELS, R. (1988). The Determinants of capital structure choice. The Journal of Finance, 43(1), 1-19. https://doi.org/10.1111/j.1540-6261.1988.tb02585.x

WOOLDRIDGE, J. M. (2010). Econometric Analysis of Cross Section and Panel Data. 2nd edition. Cambridge, Massachusetts, London, England: The MIT Press.

ZIETZ, E, SIRMANS, S. \& FRIDAY, S. (2003). The environment and performance of real estate investment trusts. Journal of Real Estate Portfolio Management, 9 (2), 127 165. https://doi.org/10.1080/10835547.2003.12089679 